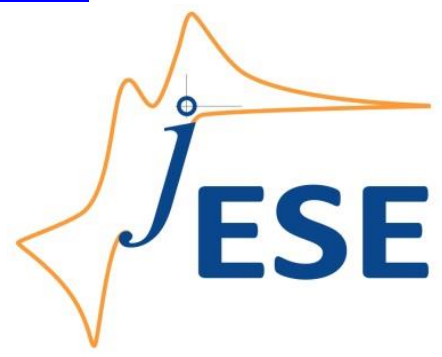

Open Access : : ISSN 1847-9286

www.jESE-online.org

Original scientific paper

\title{
Single and multi-frequency impedance characterization of symmetric activated carbon single capacitor cells
}

\author{
Suzana Sopčić ${ }^{,}$Davor Antonić ${ }^{1}$, Zoran Mandić1, Krešimir Kvastek ${ }^{2}$, \\ Višnja Horvat-Radošević2, \\ ${ }^{1}$ University of Zagreb, Faculty of Engineering and Technology, Department of Electrochemistry, \\ Marulićev trg 19, 10000 Zagreb, Croatia \\ ${ }^{2}$ Ruđer Bošković Institute, Bijenička c. 54, 10000 Zagreb, Croatia \\ ${ }^{\otimes}$ Corresponding author - E-mail: vhorvat@irb.hr
}

Received: April 9, 2018; Revised: May 4, 2018; Accepted: May 10, 2018

\begin{abstract}
Electrochemical impedance spectroscopy (EIS) technique is used for characterization of single cell symmetric capacitors having different mass loadings of activated carbon (AC). Relevant values of charge storage capacitance $\left(C_{T}\right)$ and internal resistance $(E S R)$ were evaluated by the single frequency and multi-frequency analyses of measured impedance spectra. Curve fittings were based on the non-ideal $\mathrm{R}$-C model that takes into account the parasitic inductance, contributions from electrode materials/contacts and the effects of AC porosity. Higher $C_{T}$ and lower $E S R$ values were obtained not only for the cell with higher mass of $A C$, but also using the single vs. multi-frequency approach. Lower $C_{T}$ and higher values of ESR that are generally obtained using the multi-frequency method and curve fittings should be related to the not ideal capacitive response of porous AC material and too high frequency chosen in applying the single frequency analysis
\end{abstract}

\section{Keywords}

Double-layer capacitor; electrical response; porous electrodes; storage capacitance, internal resistance

\section{Introduction}

Electrochemical capacitors/supercapacitors are high power energy storage devices composed basically from two electrodes built-up from an active material put on current collectors and immersed in a liquid ionic conductor (electrolyte) [1-8]. In these devices, energy is stored reversibly or quasy-reversibly by either ion adsorption at the electrode/electrolyte interfacial regions (electrochemical double layer capacitors - EDLC), or ion adsorption combined with some fast surface redox (faradaic) reaction (supercapacitors - SC). Various types of EDLC/SCs were already derived, including symmetric and asymmetric devices. Symmetric EDLC/SCs utilize the same 
electrode material (usually carbon) for both electrodes, while asymmetric types use different materials for electrodes, including a battery-like electrode in asymmetric hybrid devices [8-10].

Charging/discharging of an EDLC/SC device containing purely capacitive electrodes is initiated by on/off switching of $d c$ voltage $(V)$ and related to separation of charges in double-layers formed at each electrode in contact with electrolyte. The scheme of the single cell of an EDLC/SC device containing two separated and equal material electrodes (positive and negative) in an electrolyte is presented in Figure 1.

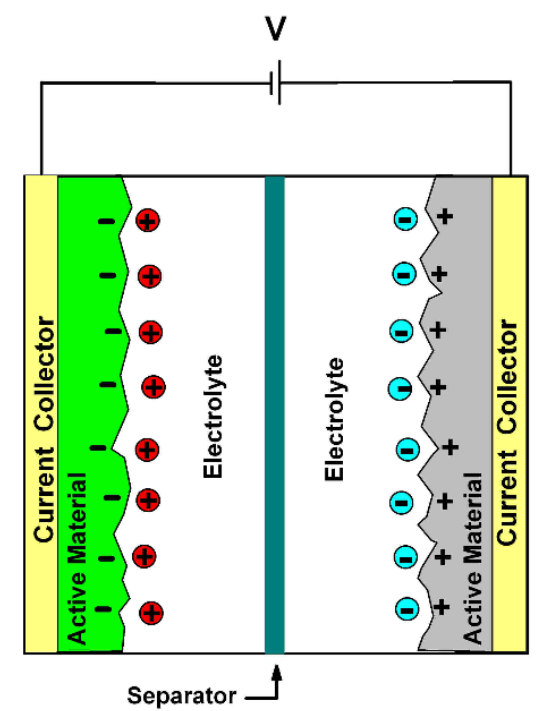

Figure 1. Schematic presentation of symmetric single cell capacitor

The charge storage ability (or capacity) of a capacitive cell is determined by the positive and negative electrode capacitance values $\left(C_{+}\right.$and $\left.C_{-}\right)$, what makes the total capacitance $\left(C_{T}\right)$ of cell to be defined as:

$$
1 / C_{\mathrm{T}}=1 / C_{-}+1 / C_{+}
$$

The overall performance of an EDLC/SC capacitive device is usually described in terms of the rated charge storage capacitance $\left(C_{T}\right), d c$ voltage $(V)$ and electrical series resistance (ESR) values. ESR comprised the internal resistance of a device including resistances of current collectors, electrodes, electrolyte, separator and all contact regions formed in between. The values of these three characteristic parameters $\left(C_{\mathrm{T}}, V\right.$ and $\left.\mathrm{ESR}\right)$ are essential for estimation of important comparative topics for EDLC/SC energy devices such as specific energy $\left(E_{s p}=C_{T} V^{2} / 2 n\right)$ and the maximal deliverable specific power $\left(P_{\mathrm{sp}(\max )}=V^{2} / 4 n \times \mathrm{ESR}\right)$. Here, $n$ denotes the normalization parameter such as mass, volume, surface area, etc. Use of high surface area porous carbon materials, conductive electrolytes with high breakdown potential and highly ion-permeable separators have strongly been recommended for attaining beneficially high $C_{T}$ and $V$ and low ESR values, i.e. high energy and high power EDLC/SC devices [11-19].

Determinations of $C_{T}$ and ESR values for devices containing new materials and also upon conventional testing of EDLC/SCS have usually been performed using different electrochemical techniques. The most commonly used are cyclic voltammetry (CV) and galvanostatic charging/discharging measurements [16-26]. By using CV experiments, $C_{T}$ values are estimated from the constant (capacitive) currents measured within a voltage window $(V)$ at low scan rates. By use of charging/discharging experiments performed at some constant current value within the voltage window $(V), C_{T}$ values are obtained from measured $V v$ s. time linear plots. At the same time, the voltage drop appearing at the initiation of the constant current discharge is commonly used for determination of ESR. 
Electrochemical impedance spectroscopy (EIS) $[25,27-29]$ is another electrochemical technique that can provide both, $C_{\mathrm{T}}$ and ESR values at various voltage $(V)$ levels of a capacitive device that should be in causal, stable, linear and time invariant conditions. EIS is usually performed by applying a small sinusoidal (current or potential) perturbing signal and measuring impedance $(Z)$ or admittance $(Y)$ vector as a function of the angular frequency $(\omega)$. Impedance vector is defined as:

$Z=1 / Y=|Z| \mathrm{e}^{\mathrm{i} \varphi}=Z^{\prime}+\mathrm{i} Z^{\prime \prime}$

In eq. (2), $|Z|$ and $\varphi$ are magnitude and phase angle of impedance vector, while $Z^{\prime}$ and $Z^{\prime \prime}$ are the real and imaginary parts in its complex number presentation. Impedances of capacitive devices are commonly measured in the linear frequency $(f=\omega / 2 \pi)$ range between $50 \mathrm{kHz}-0.01 \mathrm{~Hz}$.

Impedance spectra of EDLC/SC capacitive systems have generally been presented as Nyquist ( $Z^{\prime \prime}$ vs. $\left.Z^{\prime}\right)[11,12,17-19,21,23,24,26,28,30-42]$, Bode $(\log |z|$ and $\varphi$ vs. $\log \omega)[19,24,26,30,31,33$, $38,42]$ and complex capacitance $(Y / \mathrm{i} \omega=C)$ plots. In this last case, complex capacitance spectra can be presented as $C^{\prime \prime}$ vs. $C^{\prime}$ and/or $C^{\prime \prime}$ and $C^{\prime}$ vs. $\log \omega(\log f)$ plots $[12,18,31,33,34,37,40,42]$.

In applying of either single frequency or multi-frequency EIS method for characterization of capacitive devices, ESR and $C_{\mathrm{T}}$ values are usually obtained using the one time (lumped) constant $R-C$ model $[1,2,6,28,37]$ for a capacitive device, having the impedance/frequency response defined as:

$$
Z(\omega)=E S R+1 / i \omega C_{T}
$$

According to eq. (3), a capacitive device will behave as a pure resistor at high and pure capacitor at low frequencies, with some transition region in between. The product of ESR and $C_{T}$ determines the time constant capacitor value, ESR $\times C_{T}=\tau_{\mathrm{c}}$. This time constant characterizes the rate of a capacitor charging up to about $63 \%$ of its final capacity (or about $37 \%$ of its depletion on discharging) and is important merit in comparing EDLC/SC devices.

ESR and $C_{T}$ values can be estimated directly from measured impedance values at high $\left(E S R=Z^{\prime}{ }_{(\omega \rightarrow \infty)}\right)$ and low $\left(C_{T}=-1 / \omega Z^{\prime \prime}{ }_{(\omega \rightarrow 0)}\right)$ frequencies, respectively. The other way of identifying ESR and $C_{T}$ parameters is the curve fitting procedure. This procedure is usually made by assigning the impedance function defined by eq. (3) across the entire range of measured frequencies, where all departures can easily be detected through the least square approach.

Departure from eq. (3) has usually been noticed through appearance of inductive impedance (having positive imaginary part) at the highest frequencies $[11,17,21,24,35,36,41]$ and another one impedance showing characteristic $-45^{\circ}$ phase angle in the transition region between pure resistive and pure capacitive impedance responses [2,18,24,31-36,38-41]. Whereas inductive impedance response has usually been observed for low impedance (highly capacitive) systems, the characteristic $-45^{\circ}$ phase angle impedance response is almost always noticed in impedance spectra of capacitive devices with highly porous electrodes. Therefore, this impedance was usually ascribed to a distributed electrode structure, reactivity and/or porosity effects $[2,35,40]$. All these observations changed the ideal $R-C$ model described by eq. (3) to the one which takes into account the parasitic inductance and the effects of electrode porosity according to the following relation $[11,18,24,35,36,41,43,44]$ :

$$
Z(\omega)=Z_{\mathrm{L}}(\omega)+R_{\mathrm{HF}}+Z_{\mathrm{s}}(\omega)
$$

Eq. (4) shows that the total impedance of a non-ideal capacitive device is composed from three impedances, i.e. inductive impedance $\left(Z_{\mathrm{L}}\right)$, high frequency resistance $\left(R_{\mathrm{HF}}\right)$ and pore impedance $\left(Z_{\mathrm{s}}\right)$. Frequency response of an inductive impedance is defined as $Z_{L}(\omega)=i \omega L$, where $L$ is inductance that is measurable at high frequencies as $L=Z^{\prime \prime} / \omega[21,24,43]$. Frequency response of $Z_{s}$, however, is more complex as it should describe the frequency dependence of a capacitance generated at pore walls, 
as well as ionic resistance distributed within electrode pores. In order to account for $-45^{\circ}$ phase angle at high-to-medium frequencies that is followed by pure capacitive response at lower frequencies, various models of $Z_{s}(\omega)$ have already been recommended in the literature. Some of these models include either a pure capacitor in series with two or more parallel RC combinations $[24,36,41,43,44]$, or the vertical ladder network [45], both mimicking different time constants in the pores. The most frequently, however, the concept based on the De Levie's theory of porous and rough electrodes [46] has been applied by which $Z_{\mathrm{s}}(\mathrm{i} \omega)$ is ascribed to the impedance/frequency response of a single rail $R C$ transmission line element (TLE) $[2,29,35,36,39,43,44,47]$.

Whereas $C_{\mathrm{T}}$ value is beneficially increased by using highly porous carbon as electrode material, appearance of an additional resistance distributed within the pores is generally considered detrimental. This is because any additional resistance would increase internal resistance, $\mathrm{ESR}=R_{\mathrm{HF}}+R_{\mathrm{S}}(\omega)$ [31-33] and make the high-frequency resistance $R_{\mathrm{HF}}=Z^{\prime}(\omega \rightarrow \infty)$ in eq. (4) to be only a part of ESR.

For some capacitive cells, however, a semicircle impedance response has additionally been noticed at higher frequencies, i.e. between $R_{\mathrm{HF}}$ and characteristic $-45^{\circ}$ and/or vertical shape of $Z_{s}(\omega)[18,23,32,33,39,40,43]$. This impedance loop has increased ESR by another resistance component and shifted the capacitive response to smaller frequencies [32,33]. Some between many explanations for such impedance response were ascribed to the charge transfer of possible pseudocapacitive reaction, formation of a passive layer at current collectors, formation of the interfacial region between current collector and electrode material or even pure dielectric polarization effects of the bulk solution $[18,32,44]$. In spite of diverse interpretation, a semicircle in impedance spectra of capacitive devices can simply be accounted for by a resistor-capacitor $(R C)$ combination, defining its impedance/frequency response as $Z_{R C}(\omega)=R_{R C} /\left(1+i \omega R_{R C} C_{R C}\right)[32,39,40,45]$. Thereby, eq. (4) that has already been defined as the sum of three impedances becomes enlarged by inclusion of $Z_{R C}(\omega)$ impedance according to:

$$
Z(\omega)=Z_{\mathrm{L}}(\omega)+R_{\mathrm{HF}}+Z_{\mathrm{RC}}(\omega)+Z_{\mathrm{s}}(\omega)
$$

Impedance spectra defined by eq. (5) is composed of four characteristic frequency regions and described by six impedance parameters $\left(L, R_{\mathrm{HF}}, R_{\mathrm{RC}}, C_{\mathrm{RC}}, R_{\mathrm{S}}\right.$ and $\left.C_{\mathrm{S}}\right)$ that all can be determined by the curve fitting procedure. In these conditions, $C_{T}=C_{\mathrm{s}}$ and $\mathrm{ESR}=R_{\mathrm{HF}}+R_{\mathrm{RC}}+R_{\mathrm{S}}(\omega)$. In using the single frequency method, however, just contributions of different resistance components to ESR are the reason why ESR should inevitably be defined at lower frequencies $[17,19]$ and why ESR $=Z^{\prime}$ at $f=1$ $\mathrm{kHz}$ has been recommended for determination of ESR of technical capacitor devices using the single frequency EIS method [22,27].

Hereinafter, impedance characterization of the single cell $(-) A C / / A C(+)$ capacitors, prepared within realization of the ESU-CAP project of the Croatian National Foundation will be elaborated. Single and multi-frequency analyses will be performed and several approaches to analyze impedance data will be applied. The final results concerning total storage capacity $\left(C_{\mathrm{T}}\right)$ and internal resistance values (ESR) will be compared and discussed.

\section{Experimental}

\section{Preparation of single cell $A C / / A C$ capacitors}

The electrodes for $A C / / A C$ single cell capacitors were prepared from a slurry of the activated carbon (AC), carbon black and polyvinylidene difluoride (PVDF). The pre-determined weights of the slurry were coated onto Al foils pieces of $2 \mathrm{~cm}^{2}$, dried and hot-pressed, forming electrodes with 6.5 
and $20.5 \mathrm{mg}$ of active material. The single cell capacitor assembly was performed within a high purity argon filled glove-box. Glass-fiber was inserted as a separator between two electrodes and solution of $0.25 \mathrm{~mol} \mathrm{dm}^{-3}$ tetraethylammonium tetrafluoroborate $\left(\mathrm{TEABF}_{4}\right.$ ) in acetonitrile (ACN) served as the electrolyte. The capacitors containing electrodes with 3.2 and $10.2 \mathrm{mg} \mathrm{cm}^{-2}$ of the total active material were denoted as AC-1 and AC-2, respectively. All details of preparation were described previously [48].

\section{Electrochemical impedance spectroscopy}

Among various possibilities and equipment for impedance measurements [49,50], the present impedance measurements were performed using the Biologic Potentiostat SP-200 under EC-Lab software. The AC//AC cells were measured in discharged states at the open circuit voltage $(V=0.00$ $\mathrm{V}$ ) after being charged/discharged in 5 cycles between 0.00 and $2.7 \mathrm{~V}$, at $4 \mathrm{~mA} \mathrm{~cm}{ }^{-2}$ for AC-1 and 10 $\mathrm{mA} \mathrm{cm}{ }^{-2}$ for AC-2 cell, respectively. AC signal of $\pm 14 \mathrm{mV}$ amplitude was applied and impedances at 10 measured points per decade were measured in the range of $1 \times 10^{6}$ to $0.01 \mathrm{~Hz}$. Prior measurements the cells were left for about one hour to attain steady-state which was controlled by subsequent impedance measurements of each cell.

Impedance results were analyzed using the Zview (Scribner Ass.). The complex non-linear least squares (CNLS) program using a presumed model and modulus weighting mode was applied for impedance data fittings. $C_{T}$ and ESR values obtained by the single frequency method served as initial values for the fitting procedure and all parameters were stated free in calculations. Statistical criteria for defining reasonable fits were small $\left(\leq 9 \times 10^{-4}\right)$ standard deviation of the overall fit, $\chi^{2}$ :

$$
\chi^{2}=\sum_{k=1}^{N}\left[\frac{\left(Z_{k(\text { exp })}^{\prime}-Z_{k(c a)}^{\prime}\right)^{2}+\left(Z_{k(\exp )}^{\prime \prime}-Z_{k(c a l)}^{\prime \prime}\right)^{2}}{\left|Z_{k(c a) \mid}\right|^{2}}\right]
$$

In eq. (6), $Z^{\prime}, Z^{\prime \prime}, k$ and $N$ are real and imaginary impedances, particular frequency of measurement and total number of measured frequencies (data points), respectively. $|Z|$ is impedance magnitude, while "exp" and "cal" denote measured and calculated quantities. More details of corrections and statistical criteria for reasonable fits of impedance spectra are described elsewhere [51].

\section{Results and discussion}

\section{Single-frequency impedance analysis}

Figure 2 shows Nyquist ( $Z^{\prime \prime}$ vs. $Z^{\prime}$ ) plots of two tested AC//AC single capacitor cells containing two near equal electrodes with different active material mass loadings ( $A C-1$ and AC-2). Both Nyquist plots showed near vertical lines, indicating capacitive impedance responses for both AC//AC cells. Higher impedance observed for the electrode with less mass of active material $(A C-1)$ is in agreement with literature data on similar AC//AC cells [31].

ESR values that according to eq. (3) should be obtained as $Z^{\prime}(\omega \rightarrow \infty)$, are at $f=1 \times 10^{5} \mathrm{~Hz}$ estimated as $3.07 \Omega$ for the AC- 1 and $2.11 \Omega$ the AC- 2 cell. $C_{T}$ values calculated using $C_{T}=-1 / \omega Z^{\prime \prime}$ at the lowest measured frequency of $0.01 \mathrm{~Hz}$ were estimated to be $0.082 \mathrm{~F}$ and $0.297 \mathrm{~F}$ for the AC-1 and AC-2 cells, respectively. From these $C_{T}$ values, specific capacitance per unit mass of one electrode, calculated using $C_{\mathrm{sp}}\left(\mathrm{F} \mathrm{g}^{-1}\right)=4 \times C_{\mathrm{T}} / m$, where $m$ denotes the total mass of both electrodes [20], were $25 \mathrm{~F} / \mathrm{g}$ for the AC-1 and $29 \mathrm{~F} / \mathrm{g}$ for the AC-2 cell, respectively.

In another way of impedance data presentation, the concept of complex capacitance is applied due to the following capacitive impedance definition $[27,29]$ :

$$
Z(\omega)=[Y(\omega)]^{-1}=[i \omega C(\omega)]^{-1}
$$




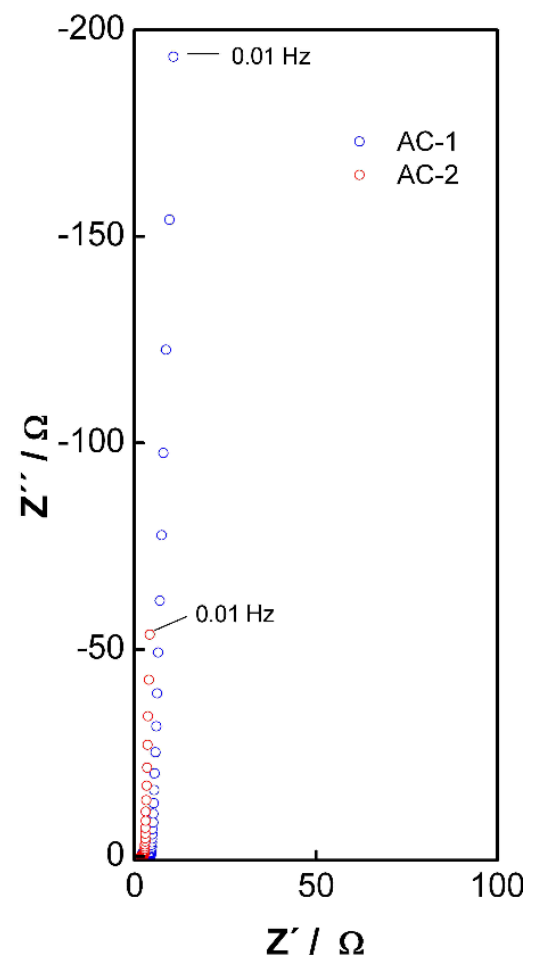

Figure 2. Nyquist ( $\mathrm{Z}^{\prime \prime}$ vs. $\mathrm{Z}^{\prime}$ ) plots of $A C-1$ and $A C-2$ capacitor cells

The complex capacitance $(C=Y / \mathrm{i} \omega)$ has also vector properties and in terms of real and imaginary components can be defined as:

$$
C(\omega)=C^{\prime}(\omega)-\mathrm{i} C^{\prime \prime}(\omega)
$$

For the pure $R-C$ model defined by eq. (3), $C^{\prime}(\omega)$ and $C^{\prime \prime}(\omega)$ are defined as:

$$
\begin{aligned}
& C^{\prime}(\omega)=-C_{\mathrm{T}} /\left(1+\omega^{2} C_{\mathrm{T}}^{2} \mathrm{ESR}\right) \\
& C^{\prime \prime}(\omega)=\omega C_{\mathrm{T}} \mathrm{ESR} /\left(1+\omega^{2} C_{\mathrm{T}}{ }^{2} \mathrm{ESR}\right)
\end{aligned}
$$

In this context, $C^{\prime}(\omega)$ defined by eq. (8a) is a term related to the energy stored, while $C^{\prime \prime}(\omega)$ defined by eq. (8b) is a term related to the energy dissipation [18,23,31,34,38,42].

As shown in Fig. 3A, $C^{\prime \prime}$ vs. $C^{\prime}$ formed semicircle shapes for both AC//AC cells, tending to zero at high and $C_{T}$ values at low frequencies. In accordance with eq. (8a), $C_{T}$ values can be scanned directly from Fig. 3B as $C^{\prime}$ at $\omega \rightarrow 0$. Such determined values were $0.082 \mathrm{~F}$ and $0.295 \mathrm{~F}$ for AC-1 and AC-2 cells, respectively. As expected, these results are equal to that calculated above using $Z^{\prime \prime}$ value at $0.01 \mathrm{~Hz}$.

Time constant $\left(\tau_{c}\right)$ values of $0.38 \mathrm{~s}$ and $0.77 \mathrm{~s}$ for $\mathrm{AC}-1$ and $\mathrm{AC}-2$ cells respectively, were estimated using the relation $\tau_{c}=\left(\omega_{c}\right)^{-1}$, where $\omega_{c}$ is the cutoff frequency at top of semicircles in Fig. $3 \mathrm{~A}$, or from maximums of $C^{\prime \prime}$ vs. log $\omega$ curve shown in Fig. $3 C[18,23,33]$. More commonly discussed and $2 \pi$ times higher values of the relaxation time constants defined as $\tau_{0}=\left(f_{0}\right)^{-1}[12,18,31,34,38,40,42]$ were estimated from the maximums of $C^{\prime \prime} v s$. log $f$ curves shown in Fig. $3 C$ as $2.39 \mathrm{~s}$ and $4.83 \mathrm{~s}$, respectively.

Both relaxation time values $\left(\tau_{c}\right.$ and $\tau_{0}$ ) can also be obtained from the phase Bode plots shown in Figure 4 , by determining frequency values $f_{0}=\omega_{0} / 2 \pi$ at which $Z^{\prime}=Z^{\prime \prime}$ and $\varphi=-45^{\circ}[30,33,40]$ as 0.42 and $0.21 \mathrm{~Hz}$, respectively. Using the relation $E S R=\tau_{0} / C_{T}, E S R$ values were calculated as $4.63 \Omega$ and $2.61 \Omega$, respectively. Somewhat higher ESR values than were estimated as $Z^{\prime}$ values at $1 \times 10^{5} \mathrm{~Hz}$, suggested some extent of departure between measured data and eq. (3). 

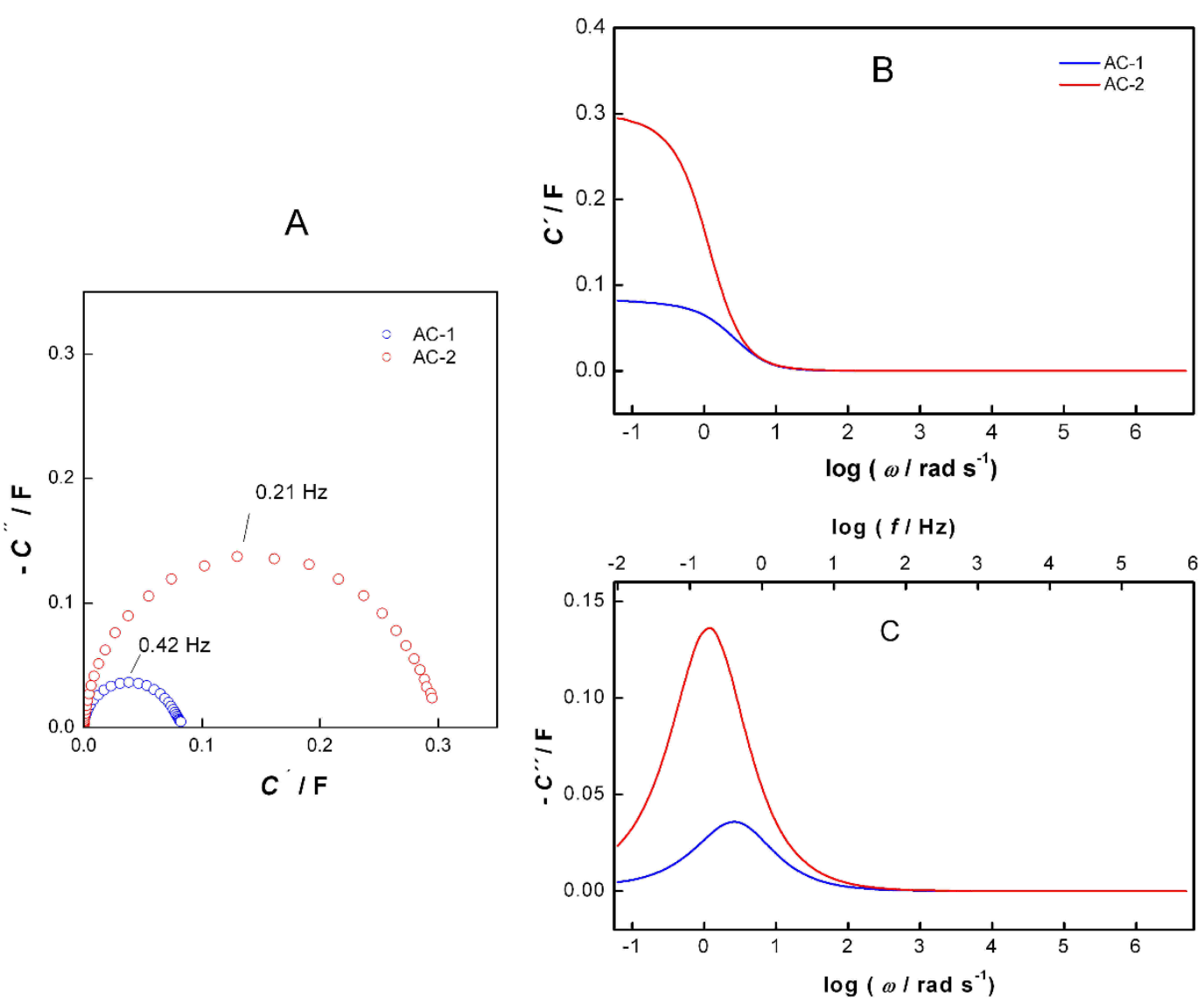

Figure 3. A) $C^{\prime \prime}$ vs. $C^{\prime}$, B) $C^{\prime}$ vs. $\log \omega$ and C) $C^{\prime \prime}$ vs. $\log \omega$ and $\log f$ dependences of $A C-1$ and $A C-2$ capacitor cells

Bode presentation of a pure $R-C$ combination described by eq. (3) is expected to show a linear magnitude line with $0^{\circ}$ phase angle at higher frequencies and a sloping linear line with $-90^{\circ}$ phase angle at lower frequencies. Certain discrepancies from this expectance can be noticed in Figure 4 as appearance of phase angles different than $0^{\circ}$ (including positive values) at the highest frequencies of impedance spectra of both single capacitor cells.
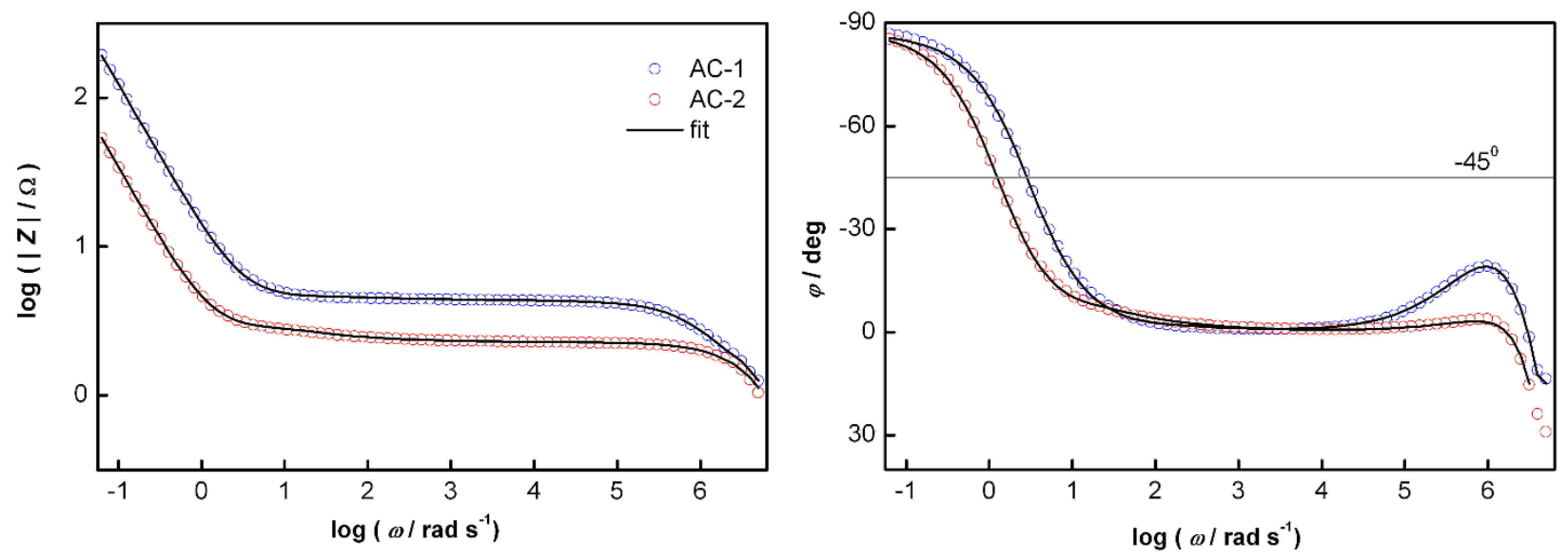

Figure 4. Bode ( $\log |\mathrm{Z}|$ and $\varphi$ vs. $\log \omega)$ plots of $A C-1$ and $A C-2$ capacitor cells

Figure 5 shows more precisely that almost ideal resistive and/or capacitive responses predicted by eq. (3) and labeled by dashed lines are obtained only within limited ranges of frequencies $[21,24,28,30,35]$. Vertical lines in Fig. $5 A$ shows that frequency independent $Z$ ' values, suggesting 
almost pure resistive cell responses, are for both $A C / / A C$ cells obtained within limited regions of high to medium frequencies.

A

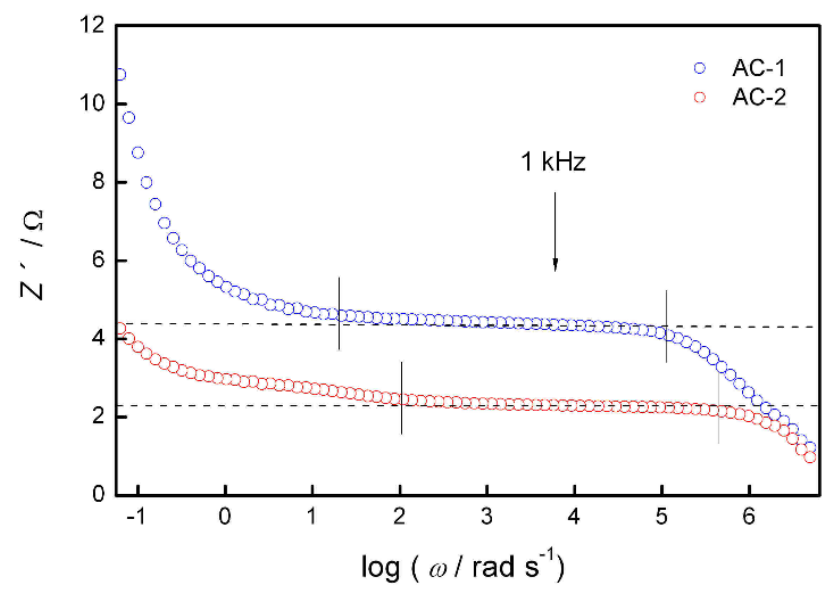

B

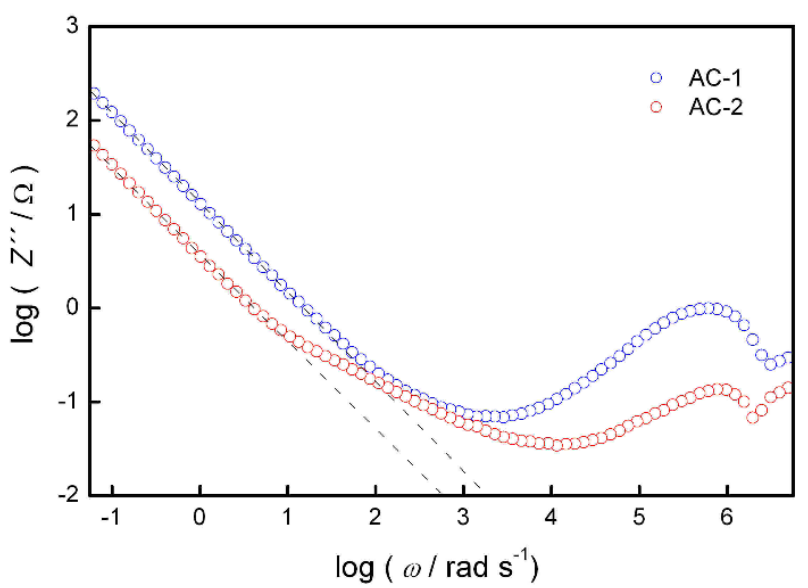

Figure 5. A) Z' and B) $\log Z^{\prime \prime}$ vs. $\log \omega$ dependences of $A C-1$ and $A C-2$ capacitor cells

The estimated ESR values at the recommended $1 \mathrm{kHz}$ frequency $[22,24,28,33$ ] (denoted by the arrow in Figure 5A) are higher than those obtained as ESR $=Z^{\prime}$ at $f=1 \times 10^{5} \mathrm{~Hz}$ and are equal to 4.36 $\Omega$ and $2.29 \Omega$ for the AC- 1 and AC- 2 cells, respectively. Fig. 5B shows that the sloping linear lines, suggesting pure capacitive responses are observed at $\omega<100(<15 \mathrm{~Hz})$ for the AC-1 cell and at $\omega<$ $10(<1.5 \mathrm{~Hz})$ for the AC-2 cell, respectively. Pure capacitive responses squeezed to low frequency region have already been noticed in Figure 4.

All these results suggest that the $R-C$ model described by eq. (3) is insufficient to present impedance of $A C / / A C$ capacitor cells but can be used as an approximation at rather low frequencies only. Therefore, in using the single frequency method, $C_{T}$ should be estimated at the lowest measured frequency, while ESR values should not be estimated at too high frequencies $[24,31-33,35]$.

\section{Multi-frequency impedance analysis}

As has already been stated in the Experimental part, impedance spectra of both AC//AC cells were measured over eight decades of frequencies $\left(10^{6}-0.01 \mathrm{~Hz}\right)$. The results of CNLS fittings of eq. (3) to measured impedance spectra of both AC//AC cells are listed in Table 1 . In spite of acceptable standard deviations obtained for $C_{T}$ and ESR parameters values, huge $\chi^{2}$ values have indicated the complete fail of the $R-C$ model for both AC//AC capacitor cells. As is also shown in Table 1 , similar has happened after use of the $R-$ CPE model, where pure capacitive impedance in eq. (3) is replaced by impedance of the constant phase element (CPE) $[26,40,43]$. Impedance of CPE, $Z_{C P E}(\omega)$ defined by eq. (9) has usually been applied in order to account for some inclination from the ideal vertical capacitive line in Nyquist plots and phase angle different than $-90^{\circ}$ in Bode plots and ascribed to surface inhomogeneities of various kinds $[26,40,43]$.

$$
Z_{\text {CPE }}(\omega)=1 / T(i \omega)^{\alpha}
$$

In eq. (9), $Z_{\mathrm{CPE}}(\omega)$ is described by two frequency independent parameters ( $T$ and $\alpha$ ), where $T$ becomes pure capacitive parameter $C$ for $\alpha=1$. For $\alpha \neq 1$ and in the terms of eq. (3), the effective capacitance value, $\left(C_{T}\right)_{c}$, can be calculated using eq. (10) $[52,53]$ :

$$
\left(C_{T}\right)_{c}=T^{1 / \alpha} \times \operatorname{ESR}^{(1-\alpha) / \alpha}
$$


Table 1. Results of CNLS fittings of $C-R$ and $R-C P E$ models to impedance spectra $\left(10^{6}-0.01 \mathrm{~Hz}\right)$ of $A C / / A C$ capacitor cells.

\begin{tabular}{rccccccc}
\hline AC//AC & Model & ESR $/ \Omega$ & $C_{\mathrm{T}} / \mathrm{F}$ & $T / \mathrm{Fs}^{\alpha-1}$ & $\alpha$ & $*\left(C_{\mathrm{T}}\right)_{\mathrm{c}} / \mathrm{F}$ & $\chi^{2}$ \\
\hline \multirow{2}{*}{$\mathrm{AC}-1$} & Eq. (3) & $4.06 \pm 0.08$ & $0.080 \pm 0.003$ & --- & -- & -- & 11 \\
\cline { 2 - 8 } & Eqs. (3)+(9) & $4.01 \pm 0.08$ & -- & $0.077 \pm 0.002$ & $0.95 \pm 0.02$ & 0.072 & 6.38 \\
\hline \multirow{2}{*}{ AC-2 } & Eq. (3) & $2.33 \pm 0.03$ & $0.286 \pm 0.008$ & -- & -- & -- & 8.23 \\
\cline { 2 - 8 } & Eqs. (3)+(9) & $2.28 \pm 0.03$ & --- & $0.261 \pm 0.008$ & $0.92 \pm 0.01$ & 0.249 & 3.57 \\
\hline
\end{tabular}

$*\left(C_{\mathrm{T}}\right)_{\mathrm{c}}$ - calculated by eq. (10)

Fails of either the $R-C$ model described by eq. (3) or $R-C P E$ model described by eq. (3) combined with eq. (9) in the curve fittings of impedance data measured at frequencies from $10^{6}$ to $0.01 \mathrm{~Hz}$, pointed to another impedance(s) influencing the measured impedance spectra of both AC//AC cells. These additional impedances can clearly be noticed in the enlarged view of high-to medium frequency parts of Nyquist plots presented in Figure 6. For both AC//AC cells shown in Figure 6, inductive impedance responses at the highest frequencies (region I) are followed by prominent semicircle paths (region II). Some differences between two cells, however, can be noticed at lower frequencies. Whereas for the AC-1 cell, the semicircular shape dominated down to $\sim 100 \mathrm{~Hz}$ after which an almost vertical (capacitive) response is observed, for the AC-2 cell, a semicircular shape is observed down to $\sim 1000 \mathrm{~Hz}$ and then followed by the characteristic $-45^{\circ}$ phase angle type of response (region III) being prominent down to $\sim 1 \mathrm{~Hz}$. Only below $1 \mathrm{~Hz}$, a capacitive line (region IV) becomes dominating for this $\mathrm{AC} / / \mathrm{AC}$ cell. Slow transition, or prominent $-45^{\circ}$ phase angle response (region III) for the AC-2 capacitor cell can be related to an inhibited transport of electrolyte within a porous structure of active material having higher thickness generated by higher mass loading.

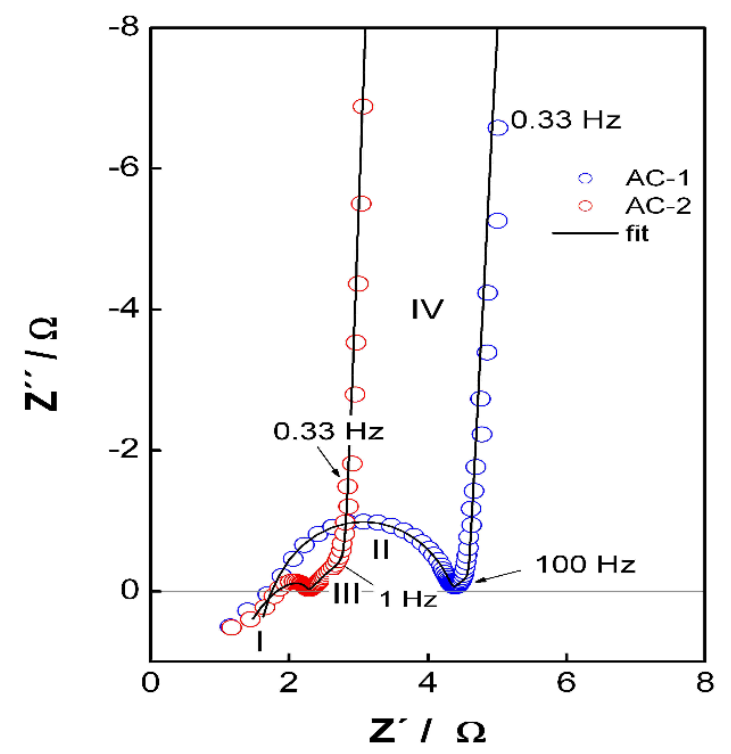

Figure 6. High-to-medium frequency region of Nyquist plots of AC-1 and AC-2 capacitor cells

Nyquist plots with four characteristic shapes (I-IV), i.e. (inductive, semicircular, $-45^{\circ}$ and capacitive), have already been observed for EDLC/SC devices $[35,43]$ and discussed here together with eq. (5). In applying eq. (5) as the impedance model equation in the fitting procedure, $Z_{s}(\omega)$ should be primarily defined. To account for the characteristic impedance $-45^{\circ}$ shape at 
intermediate frequencies followed by an almost purely capacitive response at the lowest frequencies, the TLE concept will be applied. In such a way, $Z_{s}(\omega)$ in eq. (5) is described in terms of the TLE impedance, $Z(\omega)_{T L E}$, defined by the following relation $[2,35,36,40,43,44,47]$ :

$$
Z_{\mathrm{s}}(\omega)=Z_{\mathrm{TLE}}(\omega)=R_{\mathrm{s}}\left(\mathrm{i} \omega \tau_{\mathrm{s}}\right)^{-p} \operatorname{coth}\left(\mathrm{i} \omega \tau_{\mathrm{s}}\right)^{p}
$$

For highly electronically conducting porous layer, $R_{\mathrm{s}}$ and $C_{\mathrm{s}}=\tau_{\mathrm{s}} / R_{\mathrm{s}}$ in eq. (11) denote the total electrolyte resistance within pores and double-layer capacitance induced at pore walls. In the ideal case, the exponent $p=0.5$, but due to the same reasoning as for CPE impedance defined by eq. (9), the exponent $p$ in eq. (11) can be lower than ideal $0.5[35,40]$, thus making $C_{\mathrm{s}}$ to be similar in its explanation to the CPE parameter $T$ [51]. The characteristic time constant $\left(\tau_{\mathrm{s}}\right)$ that is determined by pore and electrolyte properties is directly responsible for the characteristic shape of impedance/frequency response. At two $\omega$ limits, eq. (11) with $p=0.5$ becomes reduced to [2,35]:

$$
\begin{aligned}
& Z_{\mathrm{s}}(\omega \rightarrow \infty)=\left(R_{\mathrm{s}} / C_{\mathrm{s}}\right)^{0.5}(\mathrm{i} \omega)^{-0.5} \\
& Z_{\mathrm{s}}(\omega \rightarrow 0)=R_{\mathrm{s}} / 3+1 /(\mathrm{i} \omega) C_{\mathrm{s}}
\end{aligned}
$$

Now, it is easy to show that at frequencies higher than $\omega_{s}=1 / \tau_{s}$, eq. (12a) defining the phase angle of $-45^{\circ}$ is operative, while at frequencies lower than $\omega_{\mathrm{s}}=1 / \tau_{\mathrm{s}}$, eq. (12b) is operative describing the ideal $R-C$ response having the phase angle of $-90^{\circ}$.

Eq. (5) combined with eq. (11) is generally described by six frequency independent impedance parameters $\left(L, R_{\mathrm{HF}}, R_{\mathrm{RC}}, C_{\mathrm{RC}}, R_{\mathrm{S}}\right.$ and $C_{\mathrm{S}}$ ) that are for not ideal impedance responses increased for two more parameters $(\alpha$ and $p$ ). The values of these eight frequency independent impedance parameters obtained by CNLS fittings of eq. (5) involving $Z_{s}(\omega)$ defined by eq. (11) and $Z_{R C}(\omega)$ corrected by eq. (9), to measured impedance spectra of two AC//AC cells are listed in Table 2 . The corresponding fitted curves are drawn by full lines in Figures 4 and 6.

Table 2. Results of CNLS fittings of the eq. (5) combined with eq. (11) to measured impedance spectra of AC//AC capacitor cells

\begin{tabular}{ccccccccccc}
\hline $\mathrm{AC} / / \mathrm{AC}$ cell & $10^{7} \times \mathrm{L} / \mathrm{H}$ & $R_{\mathrm{HF}} / \Omega$ & $10^{6} \times T_{\mathrm{RC}} / \mathrm{Fs}^{\alpha-1}$ & $\alpha$ & $R_{\mathrm{RC}} / \Omega$ & $R_{\mathrm{s}} / \Omega$ & $\tau_{\mathrm{s}} / \mathrm{s}$ & $p$ & $* T_{\mathrm{s}} / \mathrm{Fs}^{2 \mathrm{p}-1}$ & $\chi^{2}$ \\
\hline $\mathrm{AC}-1$ & $2.60 \pm 0.01$ & $1.24 \pm 0.03$ & $4.6 \pm 0.4$ & 0.82 & $3.10 \pm 0.04$ & $0.71 \pm 0.04$ & $0.048 \pm 0.003$ & 0.48 & 0.068 & $6.9 \times 10^{-4}$ \\
\hline AC-2 & $2.77 \pm 0.01$ & $1.0 \pm 0.1$ & $3.1 \pm 0.4$ & 0.85 & $1.2 \pm 0.1$ & $1.57 \pm 0.02$ & $0.428 \pm 0.006$ & 0.49 & 0.273 & $5.3 \times 10^{-4}$ \\
\hline${ }^{*} T_{\mathrm{s}}$ calculated as $\tau_{\mathrm{s}} / R_{\mathrm{s}}$ & & & & & & & & &
\end{tabular}

Well fitted results indicated by acceptable $\chi^{2}$ values and low errors of all individual parameters have pointed that eq. (5) was a reasonable model function applied in the impedance analysis of two AC//AC capacitor cells. $C_{\mathrm{T}}$ values calculated from $T_{\mathrm{s}}$ and $p$ values from Table 2 using eq. (10) with $\alpha$ $=2 p$ are listed in Table 3 , together with ESR values calculated as ESR $=R_{\mathrm{HF}}+R_{\mathrm{RC}}+R_{\mathrm{s}} / 3$. The corresponding data obtained by the single-frequency method and impedance data plotted in Figures 2, 3 and 5 are also listed in Table 3.

Table 3. $C_{T}$ and ESR values of AC-1 and AC-2 capacitor cells obtained by single and multi-frequency methods

\begin{tabular}{|c|c|c|c|c|c|}
\hline & & \multicolumn{2}{|c|}{ AC-1 } & \multicolumn{2}{c|}{ AC-2 } \\
\hline & Frequency range & $C_{\mathrm{T}} / \mathrm{F}$ & ESR $/ \Omega$ & $C_{\mathrm{T}} / \mathrm{F}$ & ESR $/ \Omega$ \\
\hline Single frequency (Fig.3) & -- & $0.082(0.01 \mathrm{~Hz})$ & $3.07\left(10^{5} \mathrm{~Hz}\right)$ & $0.297(0.01 \mathrm{~Hz})$ & $2.11\left(10^{5} \mathrm{~Hz}\right)$ \\
\hline Single frequency (Fig.6) & -- & $0.082(0.01 \mathrm{~Hz})$ & $4.36\left(10^{3} \mathrm{~Hz}\right)$ & $0.297(0.01 \mathrm{~Hz})$ & $2.33\left(10^{3} \mathrm{~Hz}\right)$ \\
\hline Single frequency (Fig.4) & -- & $0.082(0.01 \mathrm{~Hz})$ & $4.63(0.42 \mathrm{~Hz})$ & $0.297(0.01 \mathrm{~Hz})$ & $2.61(0.21 \mathrm{~Hz})$ \\
\hline Curve fitting by eqs. (5)+(11) & $1 \times 10^{6}-0.01 \mathrm{~Hz}$ & 0.065 & 4.58 & 0.271 & 2.72 \\
\hline
\end{tabular}


Comparison of $C_{T}$ values listed in Table 3 shows that generally lower $C_{T}$ values were for both $A C / / A C$ capacitor cells obtained by the curve fitting procedure performed using eq. (5) combined with eq. (11), than by using the single frequency method and usual approximation $C_{T}=-1 / \omega Z^{\prime \prime}$ at $f=0.01 \mathrm{~Hz}$. Almost 10-20\% lower $C_{\mathrm{T}}$ values obtained for two cells using the multi-frequency method should be ascribed to influence of not ideal responses of capacitances induced at pore walls of AC electrode materials and seen through $2 p<1$ (cf. Table 2). ESR values determined by the single frequency method showed significant dependence on the chosen frequency of evaluation, suggesting significant contribution of distributed electrolyte solution resistance within porous AC electrode material to the evaluated data. The present results also show that for here characterized $\mathrm{AC} / / \mathrm{AC}$ cells, the recommended $f=1 \mathrm{kHz}$ is too high for proper ESR evaluations. Only when the frequency of ESR evaluation was rather low, ESR values become similar to that determined by the multi-frequency analysis and curve fitting procedure, where distributed resistance effects have already been taken into account by applying eq. (5) combined with eq. (11).

\section{Conclusions}

The characteristic values of total charge capacitance $\left(C_{T}\right)$ and internal resistance (ESR) of two single cell $A C / / A C$ capacitors with different quantities of active electrode materials were analyzed using the single and multi-frequency analyses of measured impedance spectra.

Single frequency $C_{\mathrm{T}}$ and ESR values were determined on the basis of ideal $C-R$ model, using impedance magnitude values measured at low and high (or already recommended) frequencies, respectively. Multi-frequency analysis involving curve-fitting procedure was performed over all measured frequencies and based on the non-ideal $R-C$ model. Non-ideal $R-C$ model assumed various impedance contributions including inductive, resistive inherent to the electrode material and/or contacts and that of AC electrode porosity.

Although close $C_{T}$ and ESR values were generally obtained, not any single frequency result was found to agree with the multi-frequency fitting results. Beneficially higher $C_{T}$ and lower ESR values were generally obtained using the single frequency method, what can be explained by an assumption of ideal capacitive response and too high frequency value of ESR evaluation. At the other side, lower $C_{T}$ and higher ESR values obtained using the multi-frequency analysis are based on anticipated contributions from porosity and pore surface inhomogeneity of AC electrode material, which all have been taken into account by the non-ideal $R-C$ model used for curve fittings.

Acknowledgements: This work is supported by the Croatian Science Foundation under the Project ESUP-CAP (IP-11-2013-8825). The authors wish to acknowledge Prof. Miran Gaberšček and Dr. Jože Moškon (National Institute of Chemistry, Ljubljana, Slovenia) for their delightful collaboration in this project.

\section{References}

[1] B. E. Conway, Electrochemical Supercapacitors: Scientific Fundamentals and Technological Applications, Kluwer Academic Publishers/Plenum Press, New York, USA, 1999.

[2] R. Kötz, M. Carlen, Electrochimica Acta 45 (2000) 2483-2498

[3] J. R. Miller, P. Simon, Science 321 (2008) 651-652

[4] A. G. Pandolfo, A. F. Hollenkamp, Journal of Power Sources 157 (2006) 11-27

[5] P. Sharma, T. S. Bhatti, Energy Conversion and Managenment 51 (2010) 2901-2912

[6] A. K. Shukla, A. Banerjee, M. K. Ravikumana, A. Jalajakshi, Electrochimica Acta 84 (2012) 165-173.

[7] Y. Wang, Y. Song, Y. Xia, Chemical Society Reviews 45 (2016) 5925-5950

[8] J. W. Long, D. Bélanger, T. Brousse, W. Sugimoto, M. B. Sassin, O. Crosnier, Materials Research Society Bulletin 36 (2011) 513-522 
[9] D. Cericola, R. Kötz, Electrochimica Acta 72 (2012) 1-17

[10] M. F. El-Kady, M. Ihns, M. Li, J. Y. Awang, M .F. Mousavi, L. Chaney, A. T. Lech, R. B. Kaner, Proceeding of the National Academy of Sciences of the United States of America, PNAS, 112 (2015) 4233-4238

[11] E. Frackowiak, F. Béguin, Carbon 39 (2001) 937-950

[12] C. Portet, G. Yushin, Y. Gogotsi, Carbon 45 (2007) 2511-2518

[13] L.-L. Zhang, X. S. Zhao, Chemical Society Reviews 38 (2009) 2520-2531

[14] M. Inagaki, H. Konno, O. Tanaike, Journal of Power Sources 195 (2010) 7880-7903.

[15] Y. Li, K. Sheng, W. Yuan, G. Shi, Chemical Communications 49 (2013) 291-293

[16] G. Xiong, C. Meng, R.G. Reifenberger, P.P. Irazoqui, T.S. Fisher, Electroanalysis 26 (2014) 30-51

[17] C. Lekakou, O. Moudam, F. Markoulidis, T. Andrews, J. F. Watts, G. T. Reed, Journal of Nanotechnology, 2011, ID 409382, 2011. DOI:10.1155/2011/409382

[18] A. Lewandowski, A. Olejniczak, M. Galinski, I. Stepniak, Journal of Power Sources, 195 (2010) $5814-$ 5819

[19] M. Arulepp, L. Permann, J. Leis, A. Perkson, K. Rumma, A. Jänes, E. Lust, Journal of Power Sources, 133 (2004) 320-328

[20] M. D. Stoller, R.S, Ruoff, Energy \& Environmental Science, 3 (2010) 1294-1301

[21] F. Rafik, H. Gualous, R. Gallay, A. Crausaz, A. Berthon, Journal of Power Sources 165 (2007) 928-934

[22] A. Burke, M. Miller, Electrochimica Acta 55 (2010) 7538-7548

[23] J. Eskusson, A. Jänes, A. Kikas, L. Matisen, E. Lust, Journal of Power Sources 196 (2011) 4109-4116

[24] N. Devillers, S. Jemei, M.-C. Péra, D. Bienaimé, F. Gustin, Journal of Power Sources 246 (2014) 596608

[25] D. K. Kampouris, X. Ji, E.P. Randviir, C. E. Banks, Royal Society of Chemistry Advances 5 (2015) 12782-12791

[26] A. Allagui, T. J. Freeborn, A. S. Elwakil, B. Maundy, Scientific Reports 638568 (2016). DOI: 10.1038/srep38568

[27] P. Kurzweil, Proceedings of the $14^{\text {th }}$ International seminar on double-layer capacitors, Deerfield Beach, FI. USA, Dec. 6-8 2004

[28] R. Kötz, M. Hahn, R. Gallay, Journal of Power Sources, 154 (2006) 550-555

[29] M. Itagaki, S. Suzuki, I. Shitanda, K. Watanabe, Electrochemistry 75 (2007) 649-655.

[30] F. Lufrano, P. Staiti, M. Minutoli, Journal of Power Sources 124 (2003) 314-320

[31] P.L. Taberna, P. Simon, J.F. Fauvarque, Journal of the Electrochemial Society 150 (2003) A292-A300

[32] C. Portet, P.L. Taberna, P. Simon, C. Laberty-Robert, Electrochimica Acta 49 (2004) 905-912

[33] A. Jänes, E. Lust, Journal of Electroanalytical Chemistry 588 (2006) 285-295

[34] P. L. Taberna, C. Portet, P. Simon, Applied Physics A: Materials Science \& Processing 82 (2006) 636646

[35] O. Bohlen, J. Kowal, D.-U. Sauer, Journal of Power Sources 172 (2007) 468-475

[36] A. Hammar, R. Lallemand, P. Venet, G. Coquery, G. Rojat, J. Chabas, https://hal.archivesouvertes.fr/hal-00411480 (01.12.2017)

[37] J. R. Miller, R. A. Outlaw, B. C. Holloway, Science 329 (2010) 1637-1639

[38] K. Sheng, Y. Sun, C. Li, W. Yuan, G. Shi, Scientific Reports 2247 (2012) DOI: 10.1038/srep00247

[39] X.-Z. Sun, X. Zhang, B. Huang, Y.-W. Ma, Acta Physico-Chemica Sinica 30 (2014) 485-491

[40] B. Batalla Garcia, A. M. Feaver, Q. Zhang, R.D. Champion, G. Cao, T.T. Fister, K.P. Nagle, G. T. Siedler, Journal of Applied Physics 104014305 (2014). DOI:10.1063/1.2949263

[41] L. Zheng, X. Hu, Z. Wang, F. Sun, D.G. Dorrell, Journal of Power Sources 287 (2015) 129-138

[42] Z. Wu, L. Li, Z. Lin, B. Song, Z. Li, K.-S. Moon, C.-P. Wong, S. L. Bai, Scientific Reports 510983 (2015). DOI:10.1038/srep10983

[43] E. Karden, S. Buller, R. W. De Doncker, Electrochimica Acta 47 (2002) 2347-2356

[44] X. Zhang, Y. Sun, J. Song, A. Wu, X. Cui, Journal of Applied Mathematics 2014, ID 726108 http://dx.doi.org/10.1155/2014/726108

[45] S. Fletcher, V.J. Black, I. Kirkpatrick, Journal of Solid State Electrochemistry 18 (2014) 1377-1387

[46] R. De Levie, Advances in Eletrochemistry and Electrochemical Engineering 6 (1967) 329-397

[47] M. Itagaki, S. Suzuki, I. Shitamida, K. Watanabe, H. Nakazawa, Journal of Power Sources 164 (2007) 415-424 
[48] S. Sopčić, Z. Mandić, D. Antonić, J. Moškon, M. Gaberšček, $6^{\text {th }}$ Regional Symposium on Electrochemistry of South-East Europe, Book of Abstracts, Balatonkenese, Hungary, 2017, p. 123.

[49] A. W. Bott, Current Separators 17 (1998) 53-59

[50] Q. Meyer, S. Barass, O. Curnick, T. Reisch, D. J. L. Brett, Journal of Electrochemical Science and Engineering 3 (2013) 107-114

[51] K. Magdić, K. Kvastek, V. Horvat-Radošević, Electrochimica Acta 117 (2014) 310-321

[52] G. J. Brug, A. L. G. Van den Eeden, M. Sluyters-Rehbach, J. H. Sluyters, J. Electroanal. Interf. Chem. 176 (1984) 275-295

[53] B. Hirschorn, M.E. Orazem, B. Tribollet, V. Vivier, I. Frateur, M. Musiani, Electrochimica Acta 55 (2010) 6218-6227

(C)2018 by the authors; licensee IAPC, Zagreb, Croatia. This article is an open-access article distributed under the terms and conditions of the Creative Commons Attribution license (http://creativecommons.org/licenses/by/4.0/) 